\title{
Aerodynamic Study of Airfoils with Leading Edge Imperfections at Low Reynolds Number
}

\author{
Luis Ayuso ${ }^{*}$, Rodolfo Sant ${ }^{\dagger}$ and José Meseguer ${ }^{*}$ \\ Universidad Politécnica de Madrid, 28040 Madrid, Spain
}

\begin{abstract}
A study has been made on the influence of the leading edge imperfections in airfoils used in different devices relating their aerodynamic performances. Wind tunnel tests have been made at different Reynolds numbers and angle of attacks in order to show this effect. Later, a quantitative study of the aerodynamic properties has been made based on the different leading edge imperfections and their size.
\end{abstract}

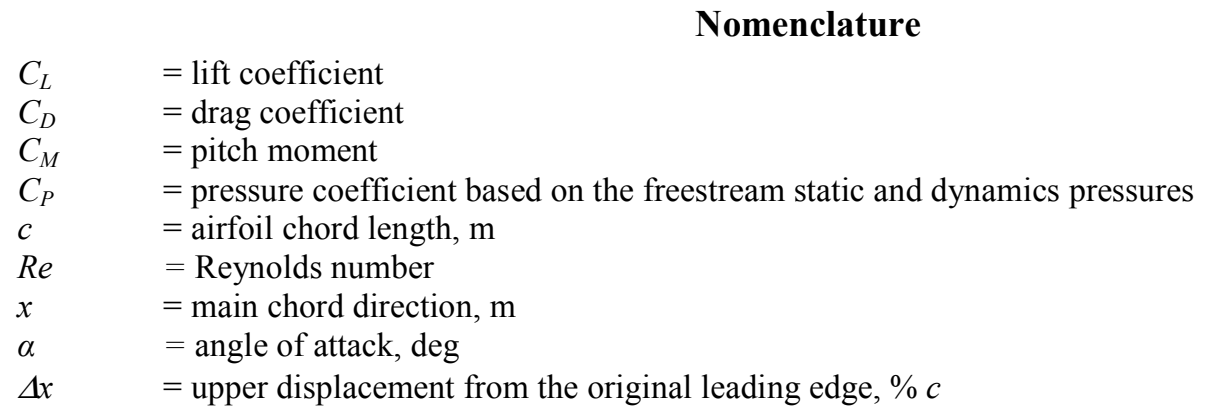

\section{Introduction}

The ${ }^{\S}$ interest of this study is based on the observation that some manufacturing processes produce imperfections in the leading edge of some wings of various vehicles, wind turbine blades or other devices that use aerodynamic profiles. Some manufacturing processes produce imperfections on the leading edge because they are manufactured in two parts, top surface and bottom surface and subsequently joined. In this last process a sliding appears between upper and lower surfaces causing a small displacement on the leading edge. Normally these imperfections are corrected through a refill and sanding processes requiring many hours of manual labor.

Therefore the initial objective of this research is to determine the level of degradation in the aerodynamic characteristics at low Reynolds numbers ${ }^{1-6}$ of these imperfections in the manufacture, and determine whether there may be a value for which it would not be necessary to correct them.

\section{Experimental Setup}

The experiments were performed in an open-circuit low-speed blow up wind tunnel in the Aerodynamics Laboratory of the Aerotecnia Department at the Universidad Politecnica de Madrid. The wind tunnel has a test section with a 1.2 by $0.16 \mathrm{~m}$ cross section and several windows, including an optically transparent one (Fig. 1). The wind tunnel has a contraction section upstream of the test section, with screen structures to provide uniform lowturbulent incoming flow to enter into the test section. Velocity distribution is $<1 \%$ outside boundary layer and the

\footnotetext{
* Professor, Department of Aerotecnia/UPM, luis.ayuso@upm.es, and AIAA Member.

$\dagger$ Professor, Department of Aerotecnia/UPM

$\ddagger$ Principal Research Scientist, IDR/UPM.
} 
mean turbulence level is $<0.5 \%$. The air speed in test section can be steadily regulated for values from 5 to $30 \mathrm{~m} / \mathrm{s}$ and therefore test the airfoils up to 500,000 Reynolds numbers.

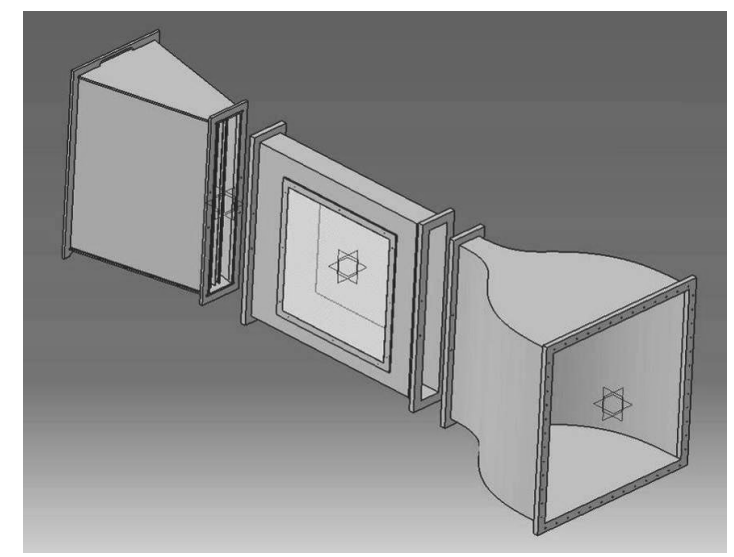

Figure 1. Wind tunnel scheme. Contraction, test-section and diffuser configuration.

The airfoil used in the present study is a NACA0012 airfoil ${ }^{7}$. Two models have been built for the tests, one of them used for forces measurement with an electronic forces balance and for the use with laser anemometry, which has a mechanism that allows you to scroll the upper on the lower surface according to graduations in \% of chord. The other model is also provided with 34 pressure taps at its median span (Fig. 2). Both models have been manufactured in a numerical control milling machine using chemical wood, with great stability and a good surface finish.

Model span is $15,6 \mathrm{~cm}$, whereas that of the wind tunnel test chamber wide is $16 \mathrm{~cm}$. No special provision has been made to avoid the gap between model and wind tunnel walls, nor to correct measure results to take into account this effect ${ }^{12}$, have been undertaken. It must be stressed that the aim of this work is to compare the aerodynamic effect of different airfoil leading edge imperfections.

The models have a $24 \mathrm{~cm}$ chord, allowing test up to 450,000 Reynolds number with a of $30 \mathrm{~m} / \mathrm{s}$ air velocity in the test section.

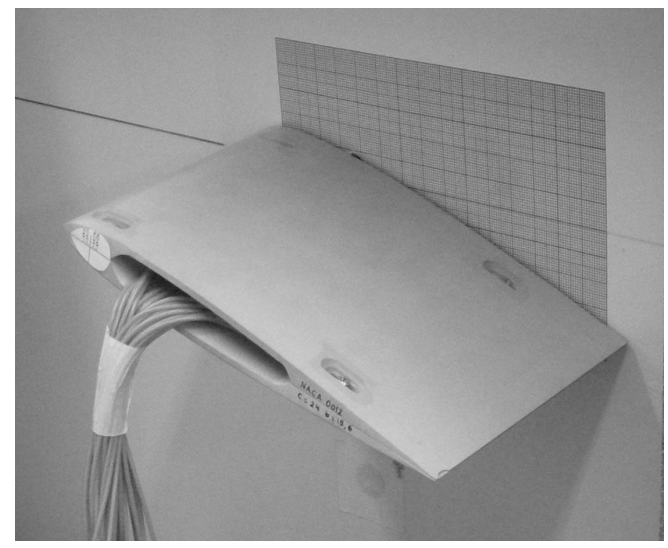

Figure 2. NACA 0012 model. Airfoil model fitted with pressure taps. 
The forces have been measured through a 3 component electronic forces balance of PLINT Company, located in one of the side walls of the test camera, which allows you to measure lift and drag forces, and pitch moment.

The pressure taps were connected to a pressure acquisition system (DSA3217, Scanivalve Corp.) for surfacepressure measurements.

Laser-Doppler anemometry (LDA) measurements are in progress. It's been performed with a DANTEC Flowlite $1 \mathrm{D}$ system. This system uses a $25 \mathrm{~mW} \mathrm{Nd}$ :YAG laser which produces green light ray of $1.35 \mathrm{~mm}$ diameter and $532 \mathrm{~nm}$. wavelength.

Models have been tested from $-4^{\circ}$ to $22^{\circ}$ angles of attack, and $\operatorname{Re}=150,000 ; 300,000$ and 450,000. For each case airfoils were studied with displacement of the upper on the lower surface of $\pm 0.25 \%, \pm 0.5 \%, \pm 0.75 \% \pm 1.0 \%$ and $\pm 1.5 \%$. Figure 3 shows the criteria of signs used to displacement $\Delta x$, it is positive when the upper side moves backward (positive sense the x-axis) and negative when it moves forward .
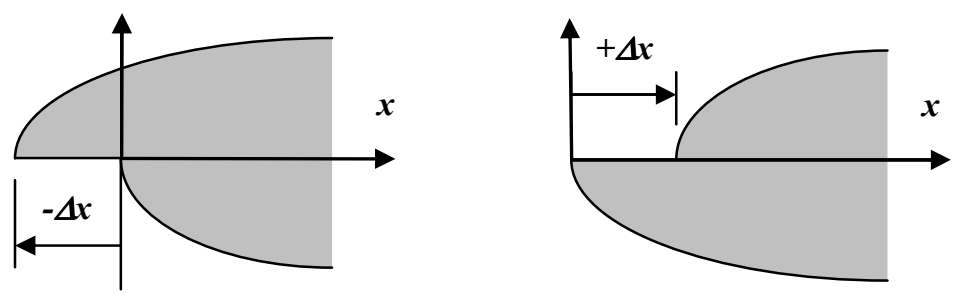

Figure 3. Criterion of signs used for the displacement. $\Delta x$ positive when the upper side of the airfoil moves backward and negative when moves forward.

In all cases the following measures were made:

- Lift coefficient $C_{L}$ and drag coefficient $C_{D}$, through the three components forces balance.

- Upper and lower surface pressure with scanivalve.

- Boundary layer air speed with LDA (in progress).

\section{Experimental Results}

The experimental results are presented in the form of $C_{L}$ and $C_{D}$ versus angle of attack. Experiments show that at the same Reynolds number small values of displacement $(\Delta x)$ cause an increase in the maximum $\mathrm{C}_{\mathrm{L}}{ }^{8}$; for higher values the trend is to have lower maximum $C_{L}$ values. If we study how the increase of the Reynolds number affects the maximum $\mathrm{C}_{\mathrm{L}}$, we will see that it increases with the Reynolds number and this happens in different proportions for all studied displacements. At the same Reynolds number the $C_{D}$ increases slightly as the size of the displacement increases. Looking at $C_{D}$ variance with the Re growth shows that minimum $C_{D}$ decreases for all displacements in different magnitude. In any case, in this paper we'll put the focus on analyzing the maximum lift coefficient of the airfoil for the different displacements $(\Delta x)$ tested.

Figure 4, 5 and 6 shows the effect of the displacement size on the lift coefficient at a fixed Reynolds number of 150,$000 ; 300,000$ and 450,000; and their influence on maximum $\mathrm{C}_{\mathrm{L}}$ values. 

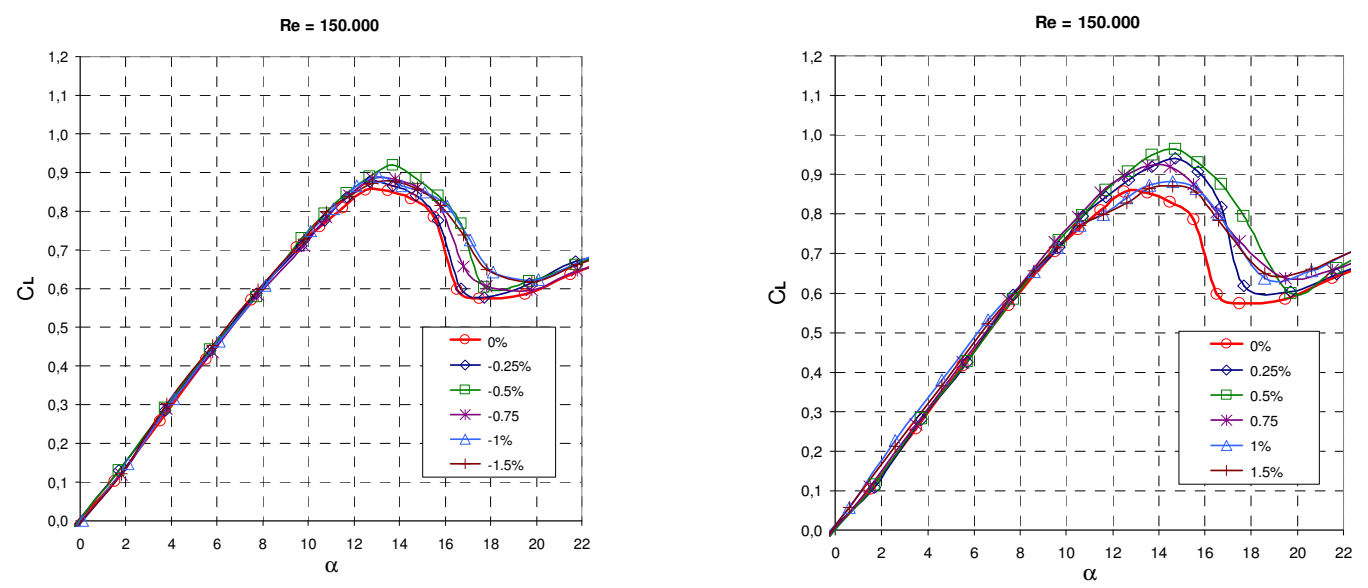

Figure 4. $\mathbf{C}_{\mathbf{L}}$ versus angle of attack. $R e=150,000$. Effect of negative and positive displacement $\Delta x$.
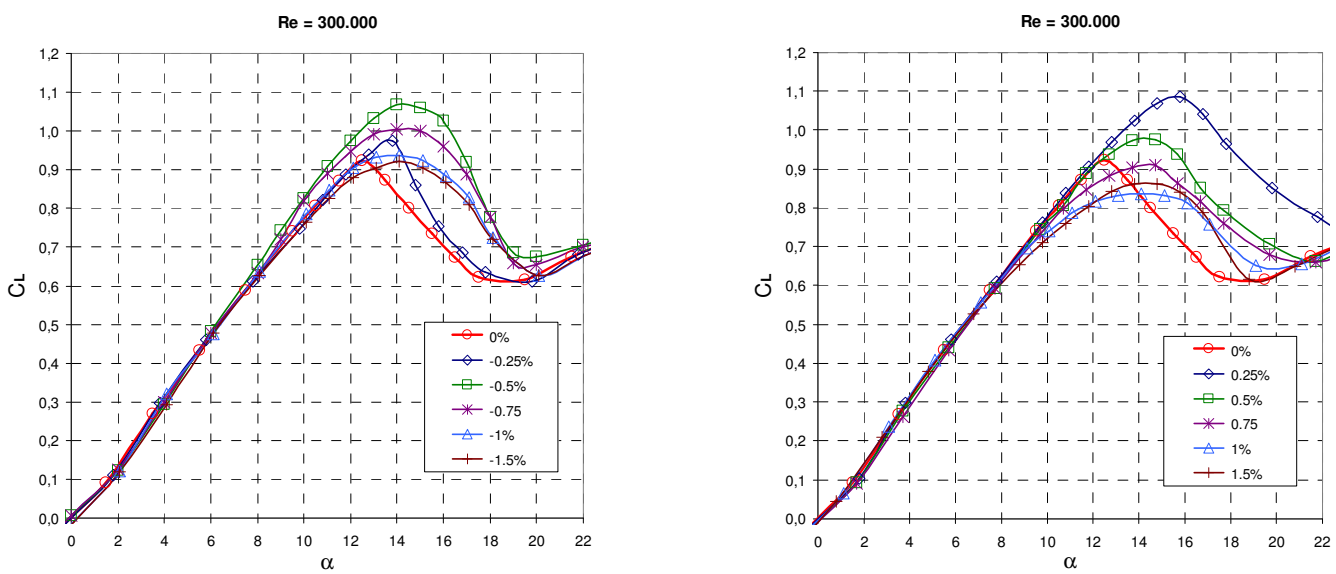

Figure 5. $\mathbf{C}_{\mathbf{L}}$ versus angle of attack. $R e=300,000$. Effect of negative and positive displacement $\Delta x$. 

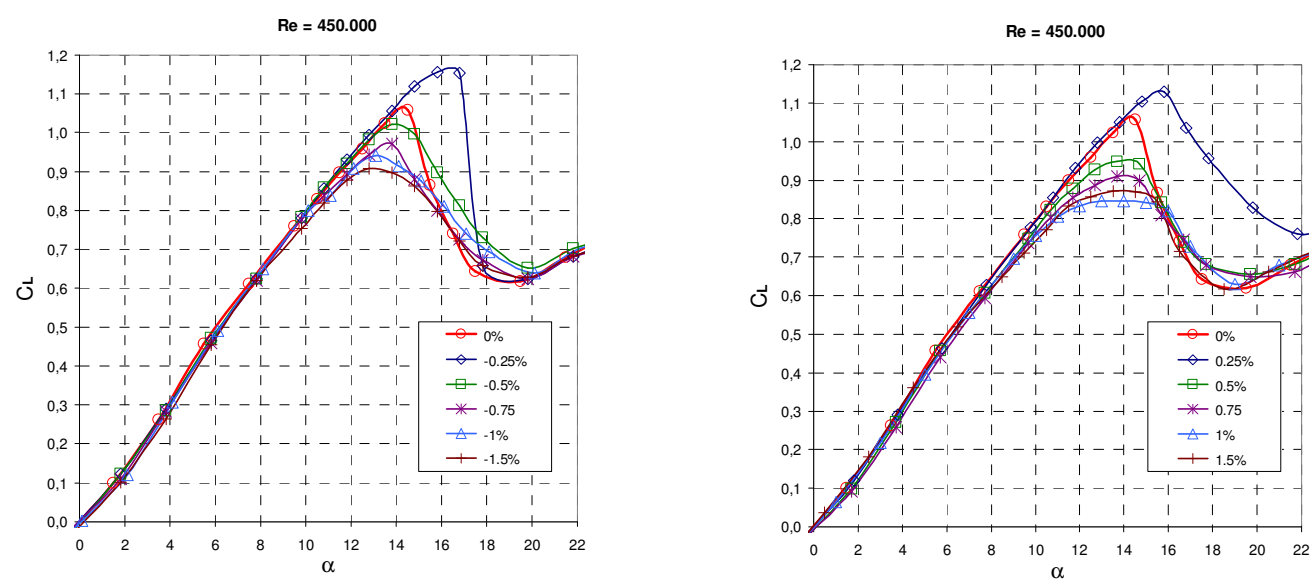

Figure 6. $\mathbf{C}_{\mathbf{L}}$ versus angle of attack. $R e=450,000$. Effect of negative and positive displacement $\Delta x$.

Figure 7, 8, 9 shows the effect of the displacement size on the drag coefficient at 150,$000 ; 300,000$ and 450,000 Reynolds number and their influence in $C_{D}$ values along the angle of attack range.
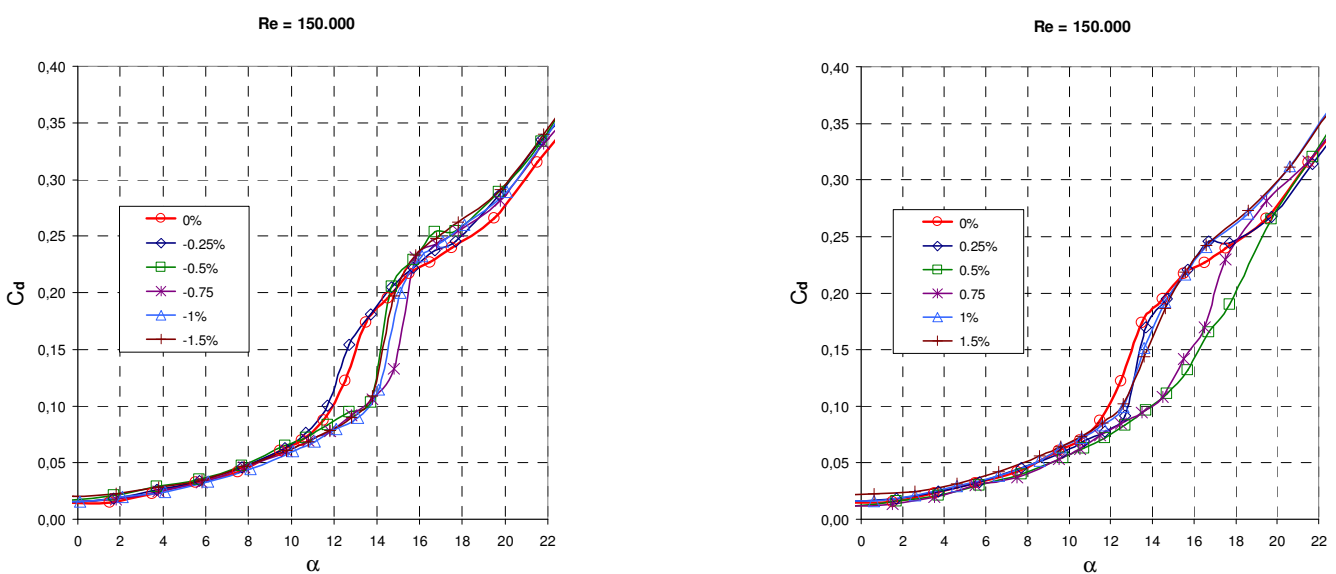

Figure 7. $\mathbf{C}_{\mathbf{D}}$ versus angle of attack. $R e=150,000$. Effect of negative and positive displacement $\Delta x$. 

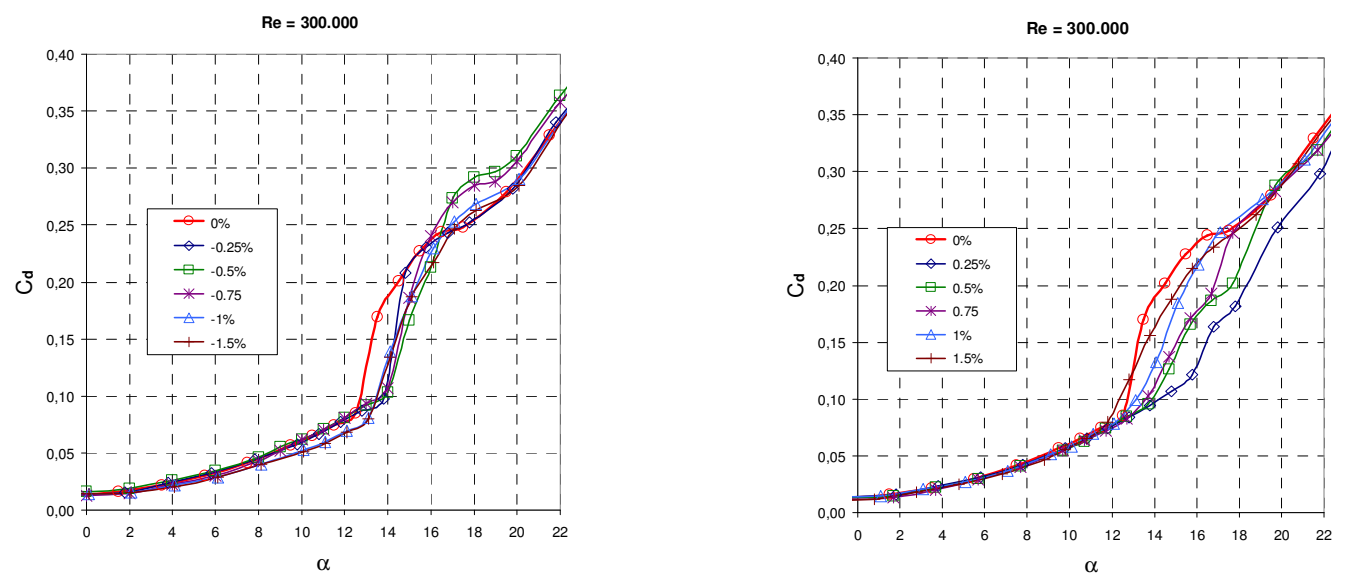

Figure 8. $\mathbf{C}_{\mathbf{D}}$ versus angle of attack. $R e=150,000$. Effect of negative and positive displacement $\Delta x$.
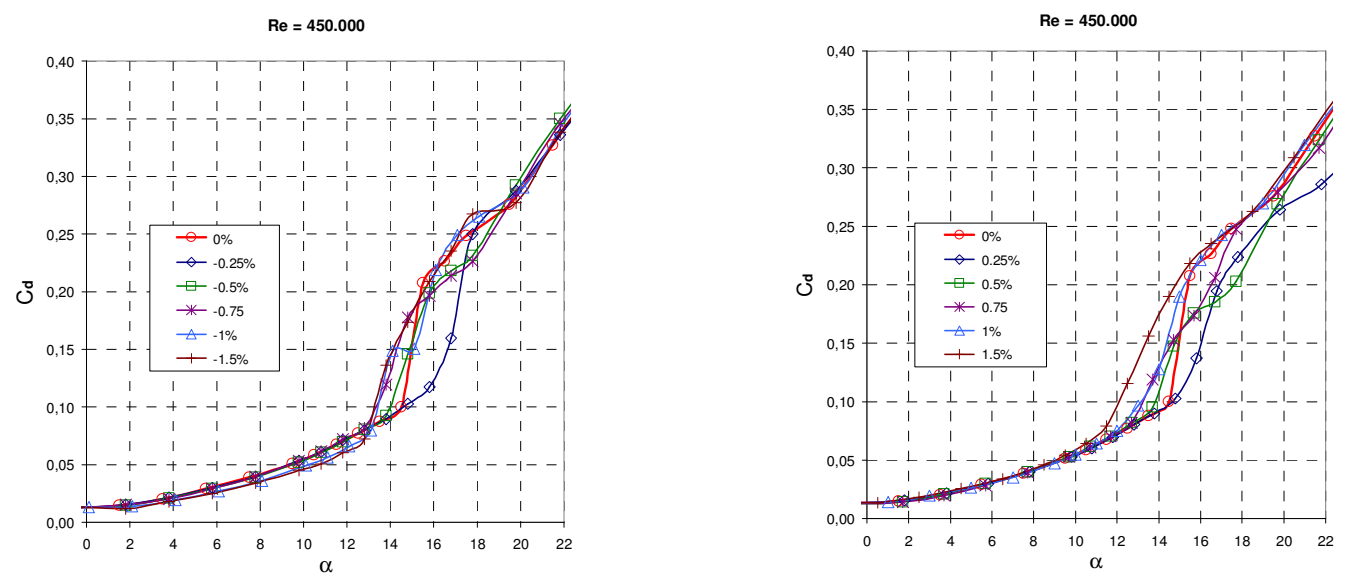

Figure 9. $\mathbf{C}_{\mathbf{D}}$ versus angle of attack. $R e=450,000$. Effect of negative and positive displacement $\Delta x$.

It must be pointed out that irrespective of the value of the Reynolds number, there are some leading edge displacement $(\Delta x)$ values which produce a noticeable growth of the lift coefficient (around some 5\%). Although such an increase depends on the Reynolds number, the maximum increase being reached at $\operatorname{Re}=3 \times 10^{5}$, where the lift grows close to $20 \%$ when compared with nominal airfoil. Although these lift increments are not symmetrical with respect to the sign of the displacement, the differences are not of significance except in the $\operatorname{Re}=3 \times 105$ case. Note also that once the displacement is fixed, the lift coefficient increases and the drag coefficient decreases as the Reynolds number grows, thus the airfoil efficiency increases with the Reynolds number. Such behaviour becomes more subtle as the displacement increases, mainly when displacements are positive. 
Those experiments carried out with pressure taps show a short laminar bubble. After laminar boundary layer separates from the airfoil surface, the flow can reattach to the surface as a turbulent shear layer. This region between the laminar separation and the reattachment is called a laminar separation bubble ${ }^{9}$. The laminar separation bubble on the airfoil is classified into a short bubble and a long bubble. With increasing angle of attack, the chordwise length of the short bubble shortens and its position moves toward the leading edge. With further increase in the angle of attack, the short bubble fails to reattach on the airfoil surface, which is known as a short bubble burst and this bubble burst causes the airfoil stall. The long bubble, which is formed after the burst, increases its chordwise length as the angle of attack is increased beyond the stall angle. The stall characteristics of the airfoil are strongly dependent upon these two types of bubbles. The negative pressure peak near the leading edge is observed when the short bubble is formed. When the long bubble is formed after the bubble burst, this negative pressure peak is destroyed and a relatively flattened pressure distribution is formed (Fig. 10). Early investigations of the short bubble mainly focused on predicting the short bubble burst ${ }^{9-11}$. Although the precise prediction of the short bubble burst has not been accomplished, it was revealed that the laminar transition and turbulent flow inside the short bubble play an important role in determining the short bubble burst.

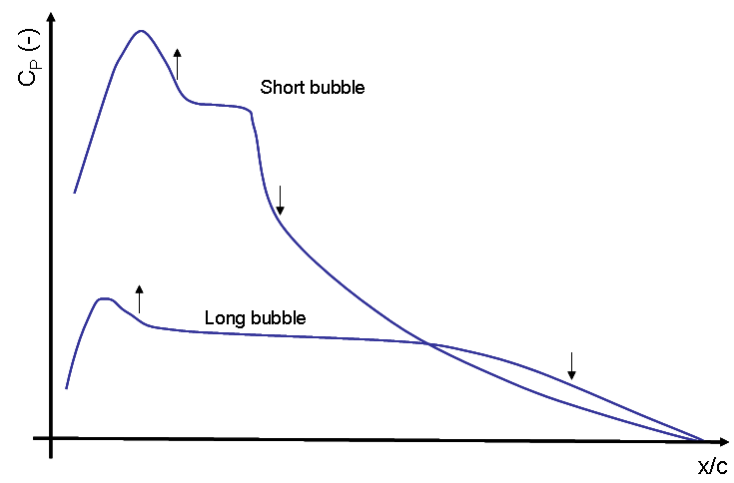

Figure 10. Pressure coefficient in laminar separation bubble.

Separation and reattachment of short and long bubbles. 
Pressure distributions along the airfoil chord for the nominal airfoil case (i.e., displacement $\Delta x=0$ ) and $\operatorname{Re}=3 \times 10^{5}$ is show in Fig. 11 (these distributions correspond to angles of attack close to the stalling angle). According to this plot, a laminar recirculation bubble appears at $\alpha=10^{\circ}, \alpha=12^{\circ}$ and $\alpha=13^{\circ}$ (the short bubble is formed when de angle of attack $\alpha$ is bellow $7 \mathrm{deg}$, see a high suction pressure near the leading edge followed by a plateau area and a sudden pressure recovery). The bubble is shorter and closer to the leading edge as the angle of attack increases (the leading edge suction peak increasing accordingly). At $\alpha=14^{\circ}$ the bubble shear layer can not reattach and the airfoil stalls (note that at $\alpha=16^{\circ}$ the boundary layer is separated in the whole airfoil upper surface).

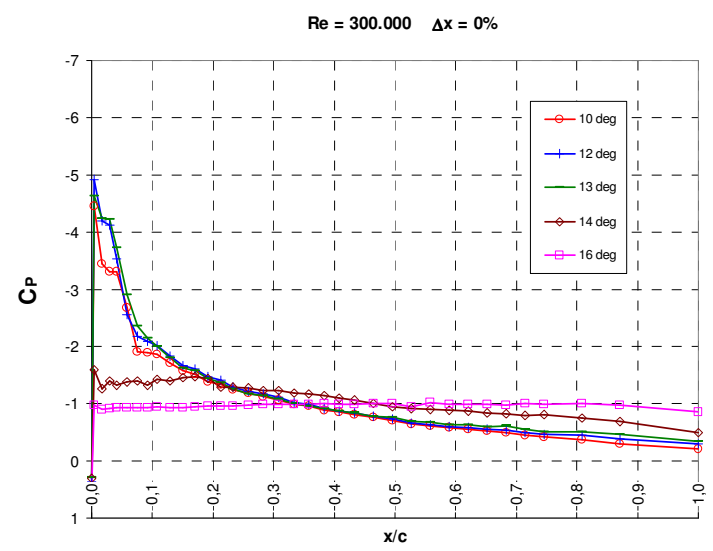

Figure 11. Pressure coefficient. Cp distribution along the upper side of the nominal airfoil. $\Delta x=0, R e=300,000$ and angles of attack close to the stalling angle.

The results corresponding to displacement $\Delta x=-0.25$ and $\Delta x=+0.25$ are shown in Figs. $12 \mathrm{a}$ and $12 \mathrm{~b}$, respectively, whereas those corresponding to $\Delta x=-0.50$ and $\Delta x=+0.50$ are depicted in Figs. 13a and 13b (these plots correspond to the same nominal airfoil and the same Reynolds number and angles of attack already considered in Fig. 11). As it can be observed in these cases experimental results reproduce the same behaviour as in Fig. 11.

Similar results are plotted in Fig. 14 and Fig. 15 for increasing values of the displacement $\Delta x$. The main difference as the displacement grows being the new boundary layer separation starts at the trailing edge. 


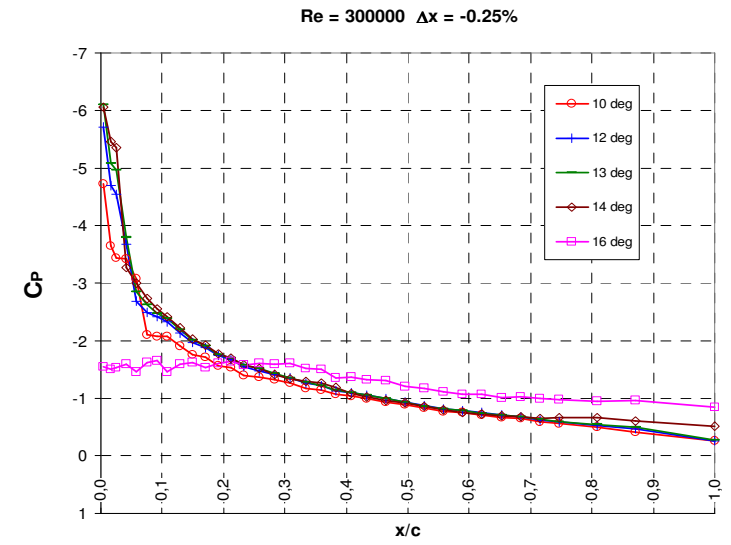

a)

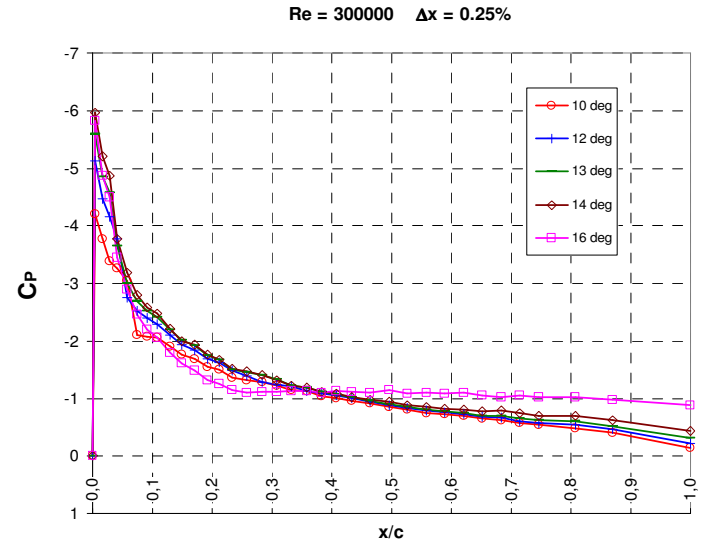

b)

Figure 12. Pressure coefficient. Cp distribution along the upper side of the airfoil. $R e=300,000$ and angles of attack close to the stalling angle. a) Displacement $\Delta x=-0.25 \%$. b) Displacement $\Delta x=+0.25 \%$.

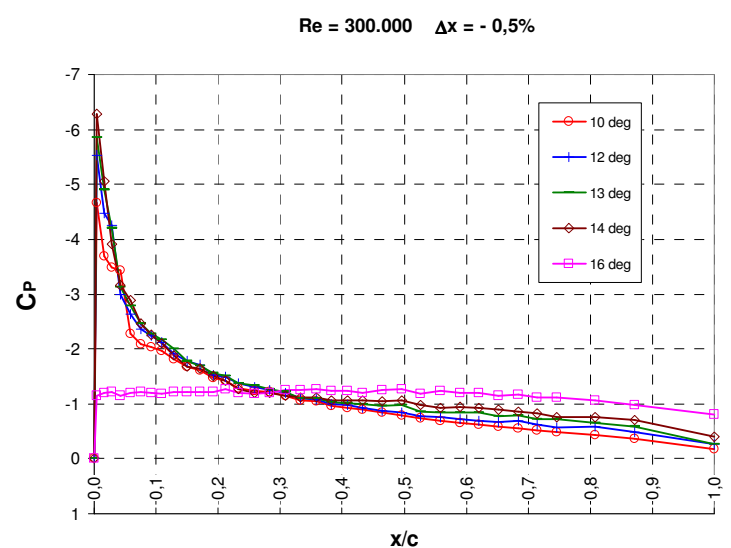

a)

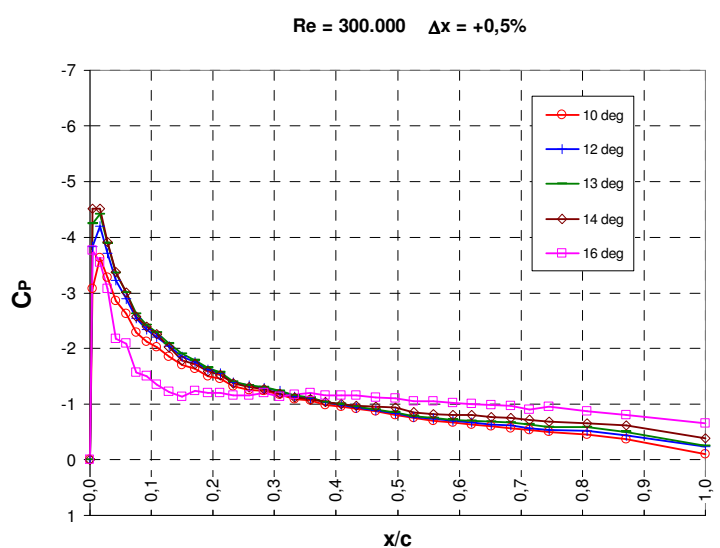

b)

Figure 13. Pressure coefficient. . Cp distribution along the upper side of the airfoil. $R e=300,000$ and angles of attack close to the stalling angle. a) Displacement $\Delta x=-0.5 \%$. b) Displacement $\Delta x=+0.5 \%$. 
$\operatorname{Re}=\mathbf{3 0 0 . 0 0 0} \quad \Delta x=-\mathbf{0}, 75 \%$

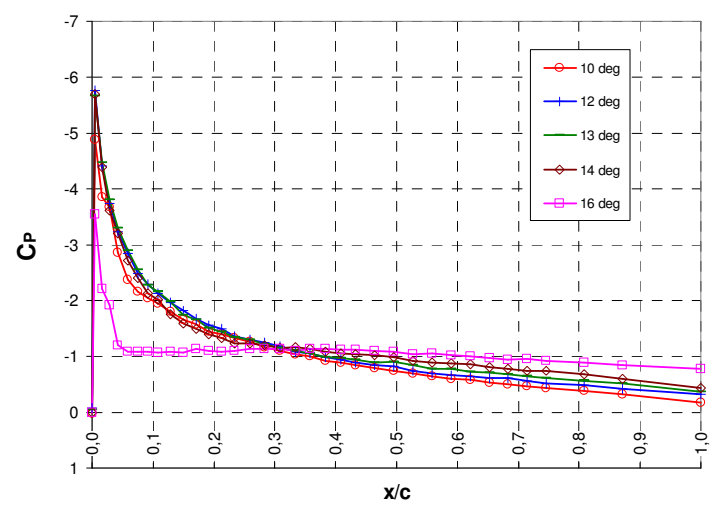

a)

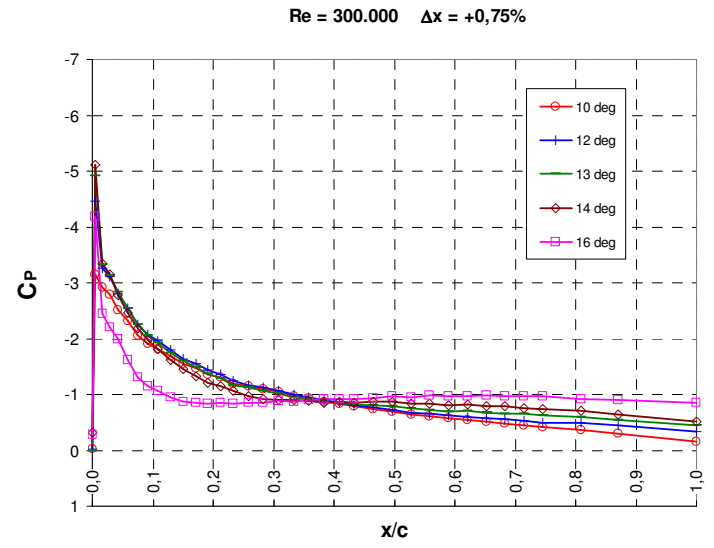

b)

Figure 14. Pressure coefficient. . Cp distribution along the upper side of the airfoil. $R e=300,000$ and angles of attack close to the stalling angle. a) Displacement $\Delta x=-0.75 \%$. b) Displacement $\Delta x=+0.75 \%$.

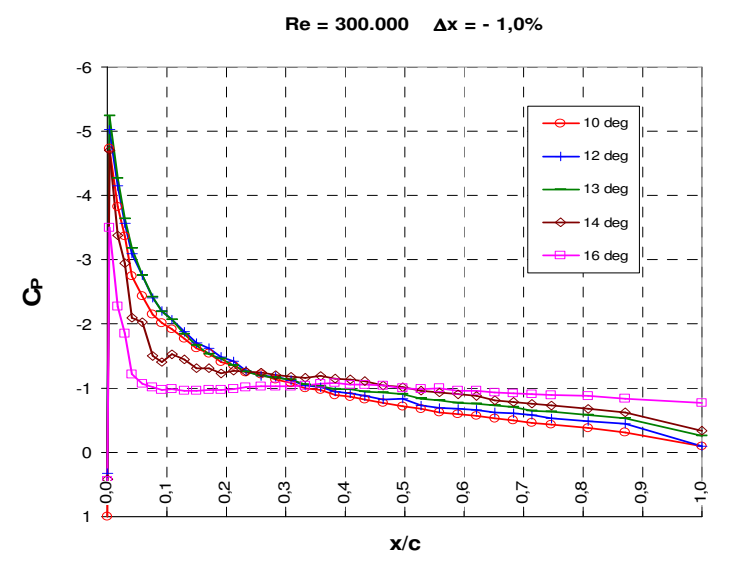

a)

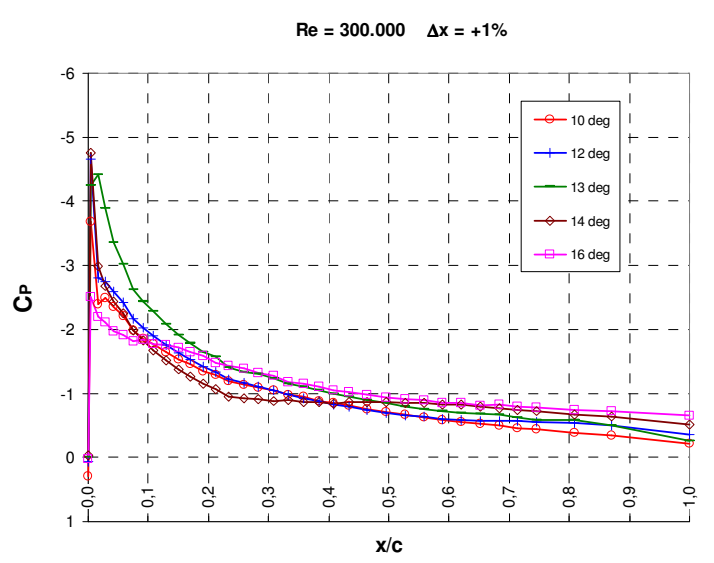

b)

Figure 15. Pressure coefficient. . Cp distribution along the upper side of the airfoil. $R e=300,000$ and angles of attack close to the stalling angle. a) Displacement $\Delta x=-1.0 \%$. b) Displacement $\Delta x=+1.0 \%$. 


\section{Conclusion}

Figures 16, 17 and 18 show the lift increasing for the different case of Reynolds number and displacement $(\Delta x)$. It is noticeable the increment of maximum lift coefficient when the displacement is small, and this occurs for all case of Reynolds number studied.

The results show a degradation of the aerodynamic characteristics as the displacement size increases, bigger for the highest values of studied Reynolds number. However, for certain combinations of low displacement size and Reynolds number, aerodynamic performance seem to improve slightly. This suggests that they could limit values of displacement that could be tolerated during manufacturing process, without that affecting considerably their aerodynamic features.

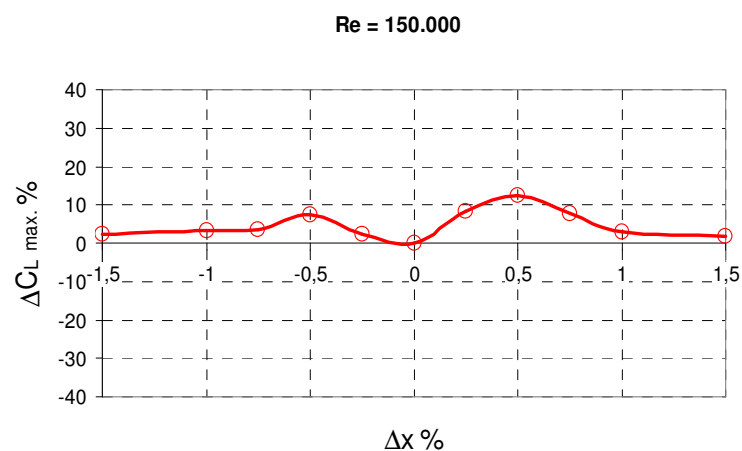

Figure 16. Increment in maximum lift coefficient. Increment in maximum lift coefficient (\%) versus displacement $\Delta x, R e=150,000$.

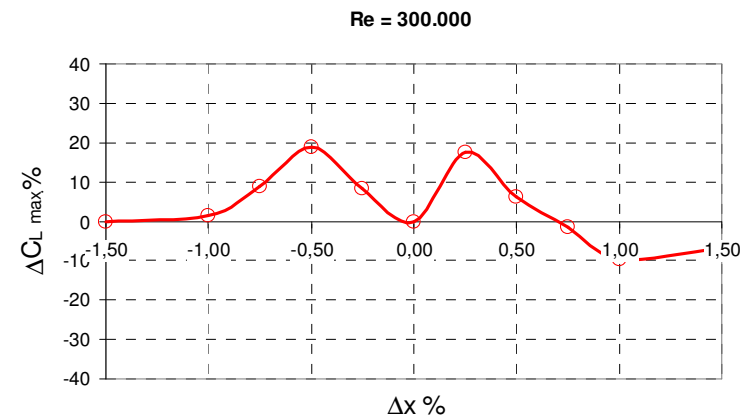

Figure 17. Increment in maximum lift coefficient. Increment in maximum lift coefficient (\%) versus displacement $\Delta x, R e=300,000$. 


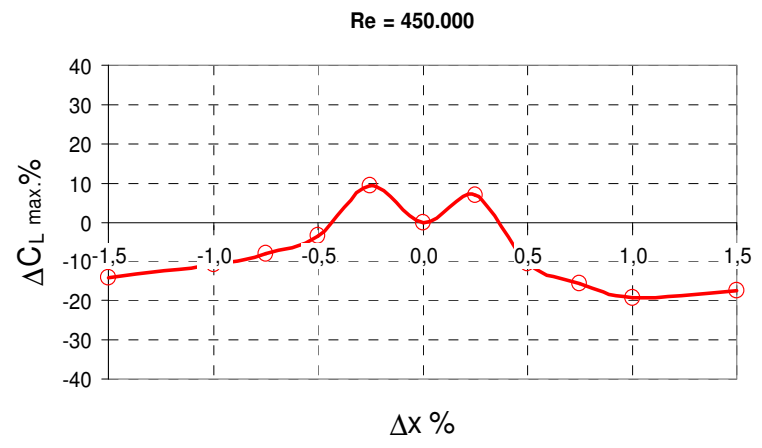

Figure 18. Increment in maximum lift coefficient. Increment in maximum lift coefficient (\%) versus displacement $\Delta x, R e=450,000$.

\section{References}

${ }^{1}$ Lissaman, P.B.S., "Low-Reynolds-Number Airfoils," Annual Review of Fluid Mechanics, Vol.15, Jan. 1983, pp. $223-239$.

${ }^{2}$ Carmichael, B.H., "Low Reynolds Number Airfoil Survey", Vol.1, NASA CR-165803, Nov. 1981.

${ }^{3}$ Nagamatsu, H.T., and Cuche, D.E., "Low Reynolds Number Aerodynamics Characteristics of Low-Drag NACA 63-208 Airfoil", Journal of Aircraft, Vol.18, No.10, 1981, pp. 833-837.

${ }^{4}$ Schmitz, F.W., Aerodynamik des Flugmodells, Verlag, Duisburg, Germany, 1957.

${ }^{5}$ Cebeci, T., "Essential Ingredients of a Method for Low Reynolds Number Airfoils", AIAA Journal, Vol.27, No.12, 1989, pp. $1680-1688$.

${ }^{6}$ Mueller, T.J. and Batill, S.M., "Experimental Studies of Separation on a Two-Dimensional Airfoil at Low Reynolds Number", AIAA Journal, Vol.20, No.4, 1982, pp. 457-463.

${ }^{7}$ Abbott, I.H., and von Doenhoff, A.E., "Theory of Wing Sections", Dover, New York, 1959.

${ }^{8}$ Jones, A.R., Bahktian, N.M. and Babinsky, H., "Low Reynolds Number Aerodynamics of Leading-Edge Flaps", Journal of Aircraft, Vol.45, No.1, 2008, pp.342-345.

${ }^{9}$ Tani, I., Low-Speed Flows Involving Bubble Separation, Progress in Aeronautical Sciences, Pergamon Press, New York, Vol. 5, 1964, pp. 70-103.

${ }^{10}$ Gault, D. E., "An Experimental Investigation of Regions of Separated Laminar Flow,” NACA TN-3505, 1955.

${ }^{11}$ Brendel, M., and Mueller, T. J., "Boundary-Layer Measurements on an Airfoil at Low Reynolds Numbers," Journal of Aircraft, Vol. 25, No. 7, 1988, pp. 612-617.

${ }^{12}$ Allen, H. J., and Vincenti, W. G., "Wall Interference in a Two-Dimensional-Flow Wind Tunnel, with Consideration of compressibility," NACA, Rept. 782, 1944. 